\title{
US Agriculture under Climate Change: An Examination of Climate Change Effects on Ease of Achieving RFS2
}

\author{
Yuquan W. Zhang ${ }^{1}$ and Bruce A. McCarl ${ }^{2}$ \\ ${ }^{1}$ RTI International, 3040 E Cornwallis Road, Research Triangle Park, NC 27709, USA \\ ${ }^{2}$ Department of Agricultural Economics, Texas A\&M University, 2124 TAMU, College Station, TX 77843, USA \\ Correspondence should be addressed to Yuquan W. Zhang; yuzhang@rti.org
}

Received 14 January 2013; Revised 4 April 2013; Accepted 23 April 2013

Academic Editor: Amani Elobeid

Copyright (c) 2013 Y. W. Zhang and B. A. McCarl. This is an open access article distributed under the Creative Commons Attribution License, which permits unrestricted use, distribution, and reproduction in any medium, provided the original work is properly cited.

\begin{abstract}
The challenges and opportunities facing today's agriculture within the climate change context are at least twofold: in addition to adapting to a potentially more variable climate, agriculture may also take on the addition role of mitigating GHG emissions-such as providing renewable fuels to replace fossil fuels to some extent. For the US, a large-scale GHG mitigation effort through biofuels production pursuant to the Renewable Fuel Standard (RFS2) is already unfolding. A question thus naturally arises for the RFS2relevant US agricultural sector: will climate change make it harder to meet the volume goals set in the RFS2 mandates, considering that both climate change and RFS2 may have significant impacts on US agriculture? The agricultural component of FASOMGHG that models the land use allocation within the conterminous US agricultural sector is employed to investigate the effects of climate change (with autonomous adaptation at farm level), coupled with RFS2, on US agriculture. The analysis shows that climate change eases the burden of meeting the RFS2 mandates increasing consumer welfare while decreasing producer welfare. The results also show that climate change encourages a more diversified use of biofuel feedstocks for cellulosic ethanol production, in particular crop residues.
\end{abstract}

\section{Introduction}

Key to agricultural production, climate and the atmosphere provide essential inputs such as solar radiation, water, and $\mathrm{CO}_{2}$ for plant and animal growth [1]. Changes in climate and the atmosphere, projected by IPCC WGI [2] as inevitable for the coming decades, raise concerns regarding the adaptive ability and/or the likely responses of the agricultural sector. The challenges and opportunities facing today's agriculture within the climate change context are, however, at least twofold: in addition to adapting to a potentially more variable climate, agriculture may also take on the additional role of mitigating GHG emissions-such as providing renewable fuels to replace fossil fuels to some extent [3]. In the US, a large-scale GHG mitigation effort through biofuels production, pursuant to the Renewable Fuel Standard (RFS2), is already unfolding. A question thus arises naturally for the RFS2-relevant US agricultural sector: will climate change make it harder to meet the volume goals set in the RFS2 mandates, considering that both climate change and RFS2 may have significant impacts on US agriculture?

Current climate change studies have shown a growing interest in "synergies" between the agriculture-based mitigation and adaptation under climate change and/or identification of an optimal mix of the two-which implicitly acknowledges the existence of some tradeoff between the two [3-6]. In other words, the issue of integrating agricultural mitigation and adaptation under climate change is increasingly mentioned and discussed, although few studies have examined if such "synergies" or the opposite exists, and if they exist, to what extent.

Readjusting the framework of "mitigation versus/in conjunction with adaptation under climate change" outlined in the previous studies, the research presented in this paper aims to examine the "synergy," or perhaps the opposite, between mitigation and climate change effects (with adaptation) that are taking place or will very likely occur within the US agricultural sector-focusing on the implementation of RFS2, 
a principally US agriculture-based GHG mitigation activity, as well as the autonomous, evolving farm-level adaptation under climate change. This study will report on the "synergy" (or the opposite) outcomes of US agricultural welfare, agricultural market equilibrium, land use change, and the RFS2 biofuel production mix with respect to a baseline in which climate change and RFS2 are absent.

The remainder of this paper is organized as follows. In the literature review part, a visit of climate change studies focusing on agriculture and a discussion of several major research approaches are presented. Then in the methodology part, this paper introduces how climate change effects and adaption activities have been incorporated in FASOMGHG to date and how the investigation of climate change interacting with RFS2 for this study is carried out. After that, this paper displays and discusses model results. Finally, this paper concludes and discusses about future research.

\section{The Literature Review}

Numerous studies have been carried out to gain an understanding about climate change impacts on agricultural production since the publication of the first IPCC report in 1990 [1]. For example, crop response simulation models that combine agronomic response of plants and management practices were developed to estimate the physical, biological, and economic outcomes in agricultural system [7]. Frequently used crop modeling systems include CERES, CENTURY, SOYGRO, and PNNL EPIC models [8-11]. These simulation models can estimate changes in both crop yields and demand for irrigation water under transient climate scenarios [10], and they are predominant tools for estimating likely climate effects on crop yields [12]. An apparent strength of the simulation models is that they can incorporate the whole distribution of weather conditions over the growing season to develop a distribution of yield and water use outcomes. However, they typically take production systems and nutrient applications as exogenous [12], limiting the involvement of farmers' behavior changes.

Another approach to study the effects of climate on crop production involves statistical estimation using cross-section data (the spatial analogue approach). This spatial analogue method attempts to forecast how cool regions would adopt warm regions' practices if climate gets warmer by comparing production activities in warm and cool regions under past and current climates [7]. Unlike crop simulation models, the spatial analogue approach is considered to have a greater success in capturing farmers' behavioral and adaptive responses [12] and possibly some other macrofactors. Nevertheless, this approach is subject to the problem of omitted variablesits likely inadequate specification of underlying physiological processes can lead to biased estimates. Moreover, the inherent assumptions of exogenous prices and policy regimes plus a lack of treatment of $\mathrm{CO}_{2}$ effects on crop yields may seriously limit the predictive power of this method.

In addition to crop simulation models and the spatial analogue method reviewed earlier, integrated assessments spanning several disciplines are carried out to explore possible outcomes of agricultural production under climate change as well. The integrated assessments typically use estimates from the aforementioned crop simulation models and econometric studies as data inputs. According to Antle (2009) [1], the most comprehensive study to date is the US Global Climate Research Program's national agricultural assessmentnamely, Reilly et al. (2003) [10]. This assessment used the ASM model-the agricultural component in FAOMSGHGto simulate the US agricultural sector under transient climate scenarios, taking into consideration climate impacts on crops, pesticide use, irrigation water supply and demand, livestock grazing supply, and international trade effects. In addition, this study carried out case studies examining climate change effects on nutrient loading to the Chesapeake Bay and groundwater depletion of the Edwards Aquifer in Texas, offering forecasts of environmental consequences under climate change. These case studies imply research opportunities that pay attention to multiple objectives, such as meeting environmental standards and adapting agriculture to climate change simultaneously.

Earlier major integrated assessments include the works of Adams et al. (1990) [13] and Adams et al. (1995) [14]. In their research, General Circulation Models (GCMs) for future climate projections, models of plant science, hydrology, and agricultural economics, are utilized. Their results suggest that irrigated cropland acreage will expand and regional patterns of US agriculture will shift under future climate change.

Collectively, the typical procedure of integrated assessments introduced earlier is as follows: firstly, obtain biophysical estimates describing changes in crop yields, irrigation water requirements, and resources availability under GCM projections of interest; then incorporate these data and their associated economic terms into economic models to generate solutions from which people can draw implications of climate change and/or evaluate economic returns to possession of or improvement in adaptation ability in agriculture.

The literature review so far has focused on agricultural climate change effects and (autonomous) adaptation to projected future climate change. Examples of real successful adaptations in US history include agricultural production in irrigated areas in the Texas High Plains and the dryland areas in the Midwestern Corn Belt [15]. Besides adapting to climate forces, producers also adapt to or respond to changes in economic and policy conditions. An examination of historic shifts in crop production locations conducted in Reilly et al. (2003) [10] suggests that nonclimate forcesgovernment policies that help limit farmers' financial losseshave likely dominated the climate forces in inducing the northward and the westward crop movements in the US, when there is evidence showing that climate has changed over the past 100 years. As for today, the US agricultural sector has actively responded to biofuel policy incentives and/or mandates in facilitating the expansion of biofuels production since the early 2000s which otherwise may not occur, as the works of McCarl and Schneider (2001) [16] and Schneider and McCarl (2003) [17] point out that without a relatively high carbon price (incentive), biofuels production in the US has no role in GHG emissions reduction among many other agriculture-based mitigation strategies. Note that so far the climate change studies that used FASOM did not include 


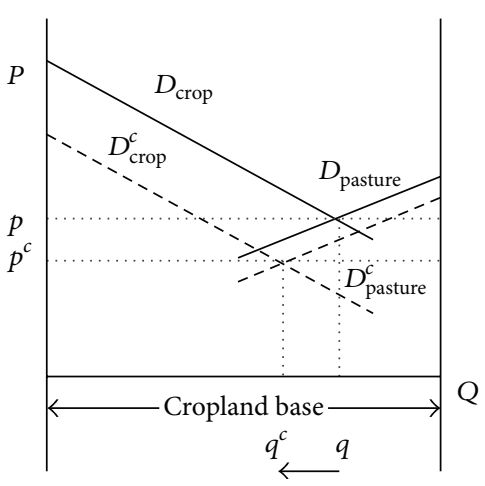

(a)

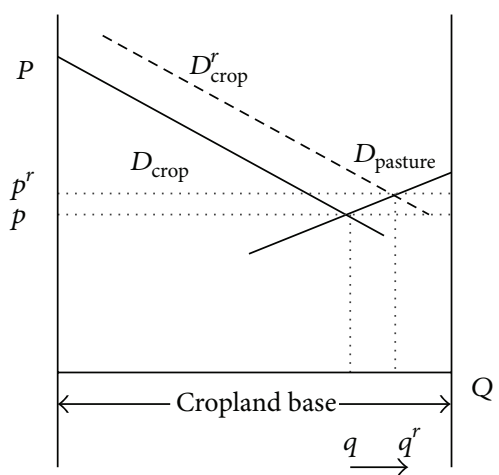

(b)

FIGURE 1: Impacts of adaptation-adjusted climate change (a) and RFS2 (b) on cropland use allocation.

the presence of US biofuels production since 2000, not to mention the RFS2 mandates.

In a well-functioning market system that rewards successful decisions and penalizes less wise decisions, a continuous and appropriate adaption to changes in environmental conditions (here including economic and policy conditions also) is a natural result [18], as demonstrated in some of the previous examples. For agriculture under climate change, this continuity in adaptation could lead to quite different outcomes from the "do nothing" counterfactuals derived under transient climate scenarios. As pointed out in Rose and McCarl (2008) [15], adaptation is nothing new but an ongoing routine in the agricultural sector. Meanwhile, Rose and McCarl (2008) [15] also noted the inertia in the socioeconomic system that can slow down taking actions to change. In FASOMGHG, each region's crop mix under new market equilibriums is constrained to fall within the convex space built by the mixes observed in the past 30 years, and for climate change scenarios, a possible 200 mile northward migration of crop mixes is allowed [19]. The research presented in this paper considers these crop-mix constraints a reasonable approach to capture both the inertia and evolving adaptation mentioned earlier.

\section{Methodology}

The agricultural component of FASOMGHG that models the land use allocation within the conterminous US agricultural sector is employed to investigate the effects of autonomous adaptation-adjusted climate change (adaptation-adjusted climate change henceforth) coupled with RFS2 on US agriculture for this study. To obtain a general picture about the implications of adaptation-adjusted climate change and RFS2 in the land use context, a simplified graphic analysis following Mendelsohn and Dinar (2009) [20] is provided in Figure 1, where $D_{\text {crop }}$ and $D_{\text {pature }}$ denote the two major competing uses-cropland demand and cropland pasture demand-for the US cropland base, respectively, with $p$ being the equilibrium cropland price.

Figure 1(b) shows that RFS2 is expected to induce a greater demand for cropland $-D_{\text {crop }}^{r}$, to the right of $D_{\text {crop }}$, resulting in an increase in cropland base allocation to cropland $\left(q^{r}>q\right)$ and a decrease in allocation to cropland pasture. A higher cropland price $\left(p^{r}>p\right)$ is also expected. Figure 1(a) shows the situation in which adaptation-adjusted climate change causes a lower national cropland demand $D_{\text {crop }}^{c}$ and a lower cropland pasture demand $D_{\text {pasture }}^{c}$, resulting in a decrease in allocation of cropland base to cropland $\left(q^{c}<\right.$ $q)$ and a lower cropland price $\left(p^{c}<p\right)$.

Note that the adaptation-adjusted climate change impacts on national cropland usage are indefinite, since the varying regional effects can lead to either a higher or a lower overall demand for cropland. Consider that crop production may respond to climate change by shifting to relatively more productive regions under a competitive market system. If the effect of higher productivity outweighs the effect of cropland reallocation, then a reduced cropland demand would result and vice versa. Similarly, if the effect of higher forage productivity is greater than the pasture reallocation effect, then a less pressing pasture demand would follow and vice versa. The equilibrium land use allocation will depend on the relative shifts of cropland and pasture demand curves. In addition, though Figure 1 shows a scenario in which adaptation-adjusted climate change and RFS2 impose opposite effects on cropland use allocation, it does not necessarily suggest that adaptation-adjusted climate change and RFS2 would counteract each other on changing agricultural welfare, as market-mediated outcomes involve price effects as well.

3.1. FASOMGHG Overview. To outline the conceptual framework of FASOMGHG, an abstract mathematical depiction of the FASOMGHG structure is presented as follows:

$$
\begin{aligned}
& \max \sum_{t}\left\{\left[\sum_{h} \int_{0}^{Z_{h t}} P_{d h t}\left(Z_{h t}\right) d Z_{h t}\right.\right. \\
&\left.-\sum_{i} \int_{0}^{X_{i t}} P_{s i t}\left(X_{i t}\right) d X_{i t}\right] \\
&\left.\times\left(\frac{1}{1+r}\right)^{t}\right\}
\end{aligned}
$$




$$
\begin{array}{ll}
\text { s.t. } \quad & Z_{h t}-\sum_{\beta} \sum_{k} c_{h \beta k t} Q_{\beta k t} \leq 0, \quad \forall h, t, \\
& -X_{i t}+\sum_{\beta} \sum_{k} a_{i \beta k t} Q_{\beta k t} \leq 0, \quad \forall i, t, \\
& \sum_{k} b_{j \beta k t} Q_{\beta k t} \leq Y_{j \beta t}, \quad \forall j, \beta, t, \\
& Z_{h t}, X_{i t}, Q_{\beta k t} \geq 0, \quad \forall i, h, \beta, k, t,
\end{array}
$$

where $P_{d}(Z)$ is the inverse demand function for commodities traded on market, and $P_{s}(X)$ the inverse supply function for purchased inputs; $Z$ presents the quantities of commodities, with $h$ being the index; $Q$ refers to the levels of production processes, including primary (e.g., corn) and secondary (e.g., biofuels) commodities production and processing, with $\beta$ indexing firm and $k$ indexing process; $X$ presents the amounts of purchased inputs, with $i$ being the index; $Y$ refers to the resources endowments such as land supply, with $j$ as its index. Also, $t$ indexes year and $r$ is the discount rate.

Turning to the mathematical structure, (1) sets the objective of maximizing the net present value of aggregate consumer and producer surpluses over time; (2) describes the relationship between final produced commodities and production processes, with coefficient $c$ giving the output yield $Z_{h}$ for production process Q; (3) connects production processes and input factors, with coefficient $a_{i \beta k}$ describing the input usage level $X_{i}$ for production process $Q$; (4) links production processes with resources endowments, with $b_{j \beta k}$ representing the production process-specific resource usage; finally (5) points out that the quantities or levels of commodities, purchased inputs, and production processes need to be nonnegative.

3.2. Incorporating Climate Change Effects. In the literature review section, the strengths of integrated assessments are discussed and the importance of including continuous, evolving adaptation is noted. To match the RFS2 schedule, the research presented in this paper sets the time scope focusing on the period of 2000-2035 and uses the Hadley and Canadian GCM projections for 2030 as the climate change background. The incorporation of climate change effects in previous climate change studies using FASOM, the predecessor of FASOMGHG, such as Reilly et al. (2003) [10], has typically involved modification of coefficients. This research also follows the same procedure and uses the same data to include the changes, as detailed next.

(a) The crop and livestock yields-coefficient $c$ in (2)are adjusted to reflect the climate change effects. Data on crop yield changes with variety and planting date adaptation arise from CERES, SOYGRO, CENTURY, and DSSAT models, as detailed in Reilly et al. (2003) [10] and Tubiello et al. (2002) [11]. Data on changes in livestock-related products production are drawn from Adams et al. (1999) [23].

(b) Coefficient (a) parameters in (3) are modified to reflect climate change induced changes in input usages. Specifically, the data on pesticide use changes
TABLE 1: Scenarios for the climate change and RFS2 study.

\begin{tabular}{lcccc}
\hline Scenario & RFS2 & \multicolumn{2}{c}{ Climate change } \\
& & None & $\begin{array}{c}\text { Hadley } \\
\text { (with adaptation) }\end{array}$ & $\begin{array}{c}\text { Canadian } \\
\text { (with adaptation) }\end{array}$ \\
\hline Base & & $\sqrt{ }$ & $\sqrt{ }$ & \\
BaseHC & & & & $\sqrt{ }$ \\
BaseCC & & & $\sqrt{ }$ & \\
\hline RFS2 & $\sqrt{ }$ & $\sqrt{ }$ & $\sqrt{ }$ \\
RFS2HC & $\sqrt{ }$ & & & \\
RFS2CC & $\sqrt{ }$ & & & \\
\hline
\end{tabular}

with respect to the Hadley and Canadian climate change projections are obtained from Chen and McCarl (2001) [24]. And the data on changes in cropping use of irrigation water are from the same source as crop yield changes specified in step (a).

(c) The right-hand-side (RHS) values in (4) are altered to reflect the climate change effects on resources availability. As documented in Reilly et al. (2003) [10], the data on changes in irrigation water supply are from Gleick and Adams (2000) [25], and the grazing supply data are modified by utilizing the crop models mentioned in step (a).

(d) International trade effects that consider the changes in grain production elsewhere in the world are incorporated in the supply functions in (1). The average of GISS and UKMO estimates from Reilly et al. (2001) [26] are used, following McCarl (2006) [27].

3.3. Phasing in Biofuels Production. As noted in the literature review section, so far the climate change studies using FASOMGHG have not included the expansion of US biofuels production since the early 2000 s yet. To reflect this biofuel growth and the RFS2 policy, further constraints are imposed in the model as follows:

$$
Z_{h^{*} t}=M_{h^{*} t}, \quad \forall h^{*}, t
$$

where $h^{*}$ indicates grain-based ethanol and cellulosic ethanol, and $M$ represents the projected or mandated volumes.

3.4. Scenarios Used. Table 1 presents the scenarios used for this study. Each scenario represents a particular combination of biofuels production assumption-with or without RFS2 - and adaptation-adjusted climate change effects, which include the information of estimates for agricultural production performance and resources availability, under the Hadley or Canadian climate change scenario.

Note that the future climate change projections, based on which the agricultural adaptation-adjusted climate change effects were derived, are assumed to be independent of the RFS2 mitigation efforts in this study due to data limitation. 
TABLE 2: Projected adaptation-adjusted climate change effects on switchgrass versus corn yields in percentage changes, 2030.

\begin{tabular}{|c|c|c|c|c|c|c|}
\hline \multirow{3}{*}{ Region } & \multicolumn{3}{|c|}{ Hadley } & \multicolumn{3}{|c|}{ Canadian } \\
\hline & \multirow{2}{*}{ Switchgrass } & \multicolumn{2}{|c|}{ Corn } & \multirow{2}{*}{ Switchgrass } & \multicolumn{2}{|c|}{ Corn } \\
\hline & & Dry & Irrig. & & Dry & Irrig. \\
\hline Corn belt & 3.98 & 10.14 & -3.25 & -15.57 & 8.84 & -7.78 \\
\hline Great plains & 3.59 & 19.20 & -3.18 & -5.64 & 18.10 & -6.20 \\
\hline Lake states & 2.01 & 50.92 & 40.45 & -3.95 & 55.20 & 47.37 \\
\hline Northeast & 1.34 & 5.16 & -3.80 & -11.40 & -0.41 & -8.70 \\
\hline Pacific northwest east & 27.54 & 17.60 & -2.50 & 10.46 & 19.20 & -7.30 \\
\hline Pacific southwest & 30.96 & 17.60 & -2.50 & 46.86 & 19.20 & -7.30 \\
\hline Rocky mountains & 8.21 & 25.55 & -4.00 & 9.86 & 21.95 & -8.80 \\
\hline South central & -16.72 & 7.60 & -1.23 & -44.25 & -2.61 & -14.56 \\
\hline Southeast & -17.70 & 3.60 & 2.10 & -41.50 & -8.20 & -15.80 \\
\hline Southwest & -11.31 & 11.60 & -3.60 & -19.09 & 3.60 & -14.50 \\
\hline
\end{tabular}

Data based on the U.S. National Assessment [10].

\section{Data}

As summarized in Reilly et al. (2001) [26], the Hadley and the Canadian scenarios employed in this study are in the middle and the high end of the 1996 IPCC projections of climate change by the year 2100 , respectively. Specifically, the Hadley scenario predicts a $1.4^{\circ} \mathrm{C}$ increase in temperature and a $6 \%$ increase in precipitation by 2030 , whereas the Canadian scenario projects an average $2.1^{\circ} \mathrm{C}$ temperature increase and a $4 \%$ precipitation decline.

In this study, most adaptation-adjusted climate change effects data for the Hadley and Canadian climate scenarios are adapted from Reilly et al. (2003) [10]. The data sources are mentioned in the FASOMGHG modification part earlier. To conserve space, the data on percentage changes in corn and switchgrass yields under the projected 2030 climate change scenarios are presented in Table 2 . These data illustrate the estimated differentiated yield outcomes of conventional crops versus dedicated energy crops. The adaptation-adjusted climate change effects on hay production derived from the CENTURY model [10] are applied to switchgrass.

Broadly speaking, the estimates of adaptation-adjusted climate change effects on dryland corn are more positive or less negative than those of switchgrass. Adaptation-adjusted climate change effects on irrigated corn are, however, negative except in the Lake States and Southeast regions. Meanwhile, the "hotter and drier" Canadian climate scenario appears to have greater negative effects on crop yields than the "milder and wetter" Hadley scenario. Notice that under all the scenarios, there are crop-specific, USDA-based technological progress rates being applied to the crop yields (and the crop residues) over the modeling period (see Adams et al. 1999 [23]). Under the climate change scenarios, the climate change effects are being applied on top of those USDA-based projections.

As for the specification of biofuels production assumptions, the No RFS2 and RFS2 representations have followed Beach and McCarl (2010) [28], which contributed to the Regulatory Impact Analysis (RIA) of RFS2 by the US Environmental Protection Agency (EPA) [22]. The No RFS2 biofuel volumes are based on AEO 2007 projections which considered the impacts of the Energy Policy Act (EPACT) of 2005 [21]; the RFS2 volumes are based on AEO 2009 projections which incorporated the provisions under the Energy Independence and Security Act (EISA) of 2007 [29]. Note that the AEO 2007 projected that corn-based ethanol would be economically competitive against conventional gasoline and its production volume would exceed the minimum 7.5 billion gallons per year (BGY) goal set in RFS1. Also, AEO 2009 projects that cellulosic ethanol and diesel would eventually become competitive liquid fuels based on National Renewable Energy Laboratory (NREL) production cost estimates. However, they indicate that by 2022, only 31 BGY instead of the full 36 BGY of ethanol-equivalents will be achieved domestically. These AEO projected biofuel volumes are market-mediated outcomes-based on an analysis using the Petroleum Market Module (PMM) in the National Energy Modeling System (NEMS). Specifically they modeled the biofuel and the conventional petroleum fuel production in a competitive market, taking into consideration the future demands and production costs (see AEO 2007 and 2009 Appendix on PMM for more details). Our analysis in this paper takes the AEO-based, EPA-compiled biofuel volumes as data inputs in building non-RFS2 and RFS2 scenarios.

Table 3 displays the key assumptions for biofuel volumes used in this study. We assume that under RFS2, the amount of agriculturally sourced cellulosic ethanol is 13.7 BGY by 2022 and beyond, and the amount of grain-based ethanol is capped at 15 BGY (see Schnepf and Yacobucci (2013) [30]). In the absence of RFS2, the cellulosic ethanol production level is kept at the minimum 0.25 BGY for periods 2010 and beyond and no more than 13.6 BGY of grain ethanol will be produced during the modeling period.

Furthermore, in NREL's engineering-economic analysis on cellulosic biofuel production [31], the nonfeedstock conversion costs are projected to decrease significantly over time, and accompanying this cost reduction is an increase in per unit ethanol yields. These two advances together result in economic viability of cellulosic biofuels production in the future. In this study, by the period 2020, the non-feedstock 
TABLE 3: Ethanol production assumptions for no RFS2 and RFS2.

\begin{tabular}{|c|c|c|c|c|c|}
\hline & & 2000 & 2010 & 2020 & 2030 \\
\hline \multirow{2}{*}{ No RFS2 } & Grain- & $2.13^{*}$ & $10.81^{* *}$ & $12.29^{* *}$ & $13.56^{* * *}$ \\
\hline & Cellulosic- & 0 & $0.25^{* *}$ & $0.25^{* *}$ & $0.25^{* *}$ \\
\hline \multirow{2}{*}{ RFS2 } & Grain- & $2.13^{*}$ & $12.83^{\#}$ & $15.00^{\#}$ & $15.00^{\#}$ \\
\hline & Cellulosic- & 0 & $0.43^{\#, \# \#}$ & $13.7^{\#, \# \#}$ & $13.7^{\#, \# \#}$ \\
\hline
\end{tabular}

*Table 11 U.S. motor fuels consumption, 2000-2005 (million gallons per year), AEO 2007 [21].

*** Table 1.2-1. AEO 2007 Reference case renewable fuel volumes (billion gallons), RIA of RFS2 [22].

*** Table A17. Renewable energy consumption by sector and source, AEO 2007 [21].

\# Table 1.2-3. Primary control case projected renewable fuel volumes (billion gallons). RIA of RFS2 [22].

\#\# The volume is derived using the formula (cellulosic ethanol + $1.7 *$ cellulosic diesel) $*(13.7 / 16)$. Consult RIA of RFS2 [22] for more details.

TABLE 4: U.S. agriculture welfare changes relative to base in \$2004 billion dollars under alternative scenarios, 2030.

\begin{tabular}{lccccc}
\hline & & No RFS2 & & \multicolumn{2}{c}{ RFS2 } \\
& Hadley & Canadian & None & Hadley & 12.36 \\
Consumer surplus & 12.95 & 9.41 & -3.12 & 9.24 \\
Producer surplus & -1.61 & -0.86 & 9.48 & 3.20 & 4.18 \\
\hline
\end{tabular}

TABLE 5: Fisher indices relative to base (base = 100) under alternative scenarios, 2030.

\begin{tabular}{lccccc}
\hline & & \multicolumn{2}{c}{ Conventional crops } & \multicolumn{2}{c}{ Livestock } \\
& & Price & Quantity & Price & Quantity \\
\hline \multirow{2}{*}{ No RFS2 } & Hadley & 83.5 & 119.9 & 96.0 & 104.0 \\
& Canadian & 86.3 & 116.0 & 97.6 & 103.2 \\
\hline \multirow{2}{*}{ RFS2 } & None & 105.6 & 98.6 & 101.0 & 98.6 \\
& Hadley & 85.2 & 119.6 & 96.3 & 103.9 \\
& Canadian & 88.6 & 115.6 & 98.0 & 103.2 \\
\hline
\end{tabular}

conversion cost for cellulosic ethanol production is assumed to decline from $\$ 3.29$ per gallon (derived from Aden (2008) [32]) in period 2000 to only $20 \%$ of that number-following the NREL (2008) based projection [31] used in Beach and McCarl (2010) [28]. And the per unit ethanol yield is assumed to increase from 71.9 gallons per ton of feedstock in period 2010 to 92.3 gallons per ton for periods 2020 and beyond, again based on NREL (2008) projections [31].

\section{Model Results}

5.1. Welfare, Price, and Production. Table 4 presents the predicted US agricultural welfare changes relative to the baseline (no climate change, no RFS2) in 2030 under alternative scenarios. As it shows, without RFS2, the "milder and wetter" Hadley climate induces a noticeably greater reduction in agricultural producer income and a larger increase in agricultural consumer surplus than the "hotter and drier" Canadian climate. With RFS2, however, both the consumer surplus and the producer income increase under climate change, though the increments in consumer surplus are slightly smaller than under the No RFS2 scenarios. Notice that in the absence of climate change, the RFS2 program reduces agricultural consumer surplus and markedly increases agricultural producer income. The comparison of the No RFS2 versus RFS2 climate change scenarios thus suggests that the RFS2 presence plays a supporting role in maintaining/enhancing the welfare accrued to agricultural producers under climate change, whereas the adaptation-adjusted climate change substantially ameliorates the negative effects of RFS2 on agricultural consumer surplus supporting the welfare accrued to consumers.

A look into the agricultural price and production indices under alternative scenarios may help understand the changes in predicted welfare. As Table 5 shows, significantly elevated crop production occurs under climate change scenarios, with the "milder and wetter" Hadley projection bringing about greater increase than the Canadian projection. The Hadley price indices are correspondingly lower than the Canadian ones. With the RFS2 presence, increases in price indices and decreases in production indices would result, implying an increased tension between supply and demand in conventional crop markets under RFS2 and, moreover, a counteracting effect of RFS2 against adaptation-adjusted climate change on conventional crop production.

For the livestock sector, both the Hadley and the Canadian climate scenarios bring about increased livestock production, due to increased supply of feed. Price indices for livestock decrease accordingly. Compared to the changes in crop production and price, the changes in the "downstream" livestock production and price are much smaller in magnitude. In addition, the RFS2 impacts appear to be small.

Reviewing the aforementioned, the noticeably higher (crop) price indices and slightly lower production indices 
TABLE 6: National average cropland rental rate under alternative scenarios, 2030.

\begin{tabular}{lcccccc}
\hline & & No RFS2 & & \multicolumn{2}{c}{ RFS2 } & \\
& None & Hadley & Canadian & None & Hadley & Canadian \\
\hline Value $(\$ /$ acre) & 94.46 & 80.80 & 85.52 & 121.78 & 90.36 & 97.53 \\
\hline
\end{tabular}

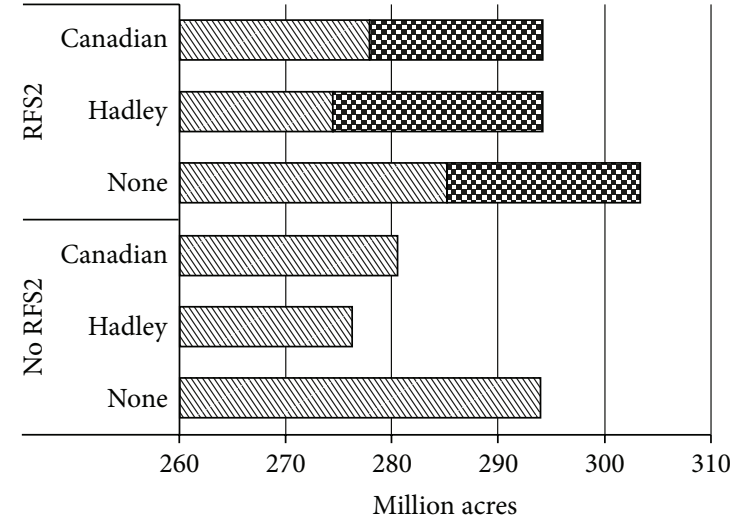

$\mathbb{0}$ Conventional crops

圈 Energy crops

Figure 2: Cropland acreage and usage under alternative scenarios, 2030.

under RFS2 correspond to the welfare-enhancing/maintaining effects of RFS2 on agricultural producer income shown in Table 3. Meanwhile, the markedly lower price indices and higher production indices for both crop and livestock under the climate change scenarios explain the beneficial impacts of adaptation-adjusted climate change on agricultural consumer surplus.

5.2. Land Use. Figure 2 displays the cropland acreage and usage between energy crops-principally switchgrass, the designated energy crop following Beach and McCarl (2010) [28] - and conventional grain and feed crops.

As shown in the figure, significantly less cropland is devoted to conventional crops production under climate change scenarios, especially the "milder and wetter" Hadley ones. Also, visibly less cropland is allocated to switchgrass production under the Canadian climate scenario, compared to the Hadley one. This reduced farming of energy crops for RFS2 purposes reflects decreased reliance on switchgrass for cellulosic feedstocks, as will be detailed in the "Fuel Ethanol Production" section next. Meanwhile, compared to the Hadley climate scenarios, the cropland acreage of conventional crops under the Canadian climate scenarios is larger, indicating the generally smaller yield-enhancing effects of the Canadian climate on crops production.

Note that the RFS2 presence also reduces the cropland allocation to conventional crops. However, this is largely driven by the competition between energy crops versus conventional crops farming rather than the generally yieldenhancing effects of adaptation-adjusted climate change.

Figure 3 portrays the net accumulative exchanges between cropland, cropland pasture, and CRP land by 2030

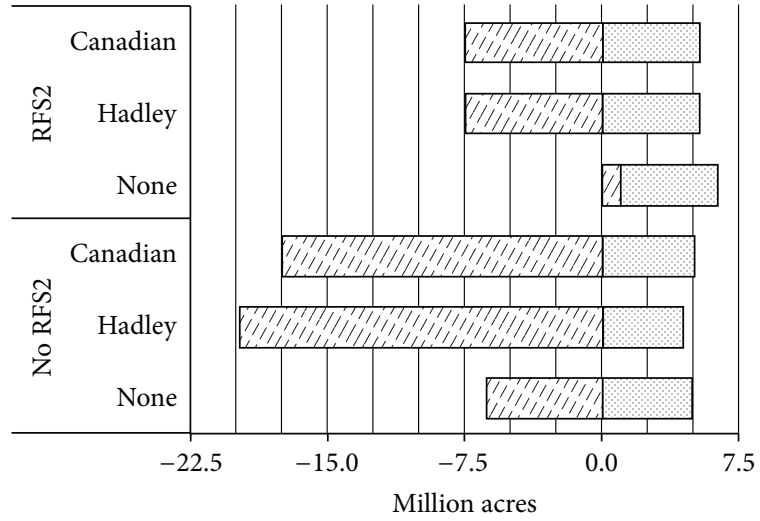

$\square$ Cropland pasture

$\square$ CRP

FIgURE 3: Land use change under alternative scenarios, 2030. under alternative scenarios. The climate change scenarios exhibit considerably greater cropland conversion to cropland pasture, with the Hadley climate inducing more such conversion than the Canadian climate. On the other hand, the RFS2 program reduces the cropland conversion, and substantially - in the absence of climate change, it is shown to even result in net cropland pasture conversion to cropland. As for CRP land, climate change has minimal effects on its reversion to cropland, whereas RFS2 induces maximum allowable CRP land reversion regardless of the presence of adaptation-adjusted climate change.

Overall, the aggregate effects of climate change and RFS2 on cropland usage (shown in Figure 2) and land use exchange (shown in Figure 3 ) are fairly small compared to the base scenario (no climate change, no RFS2). Despite that, the welfare changes brought by adaptation-adjusted climate change and RFS2 are significant-both agricultural consumer surplus and producer income increase as shown in Table 3, with climate change favoring consumer welfare and RFS2 supporting producer welfare. The comparison of land use under the base scenario and the RFS2 climate change scenarios also suggests that under climate change, with adaptation included, almost the same amount of cropland can accommodate both providing grain and feed crops for human and livestock consumption and producing RFS2relevant energy crops.

Accompanying the land use changes illustrated in Figures 2 and 3 are also changes in cropland rental rate across the scenarios, as presented in Table 6.

As the table shows, climate change scenarios exhibit lower cropland rental rates than the "none" climate change scenarios, corresponding to the reduced cropland usage 
TABLE 7: Feedstock-specific ethanol production in million gallons per year under alternative scenarios, 2030.

\begin{tabular}{|c|c|c|c|c|c|c|}
\hline & \multicolumn{3}{|c|}{ No RFS2 } & \multicolumn{3}{|c|}{ RFS2 } \\
\hline & None & Hadley & Canadian & None & Hadley & Canadian \\
\hline \multicolumn{7}{|l|}{ Cellulosic ethanol } \\
\hline \multicolumn{7}{|l|}{ Dedicated energy crops } \\
\hline Switchgrass & - & - & - & 12,744 & 12,804 & 9,011 \\
\hline Hybrid poplar & - & - & - & - & 58 & 218 \\
\hline Willow & - & - & - & 61 & 55 & 57 \\
\hline \multicolumn{7}{|l|}{ Crop residues } \\
\hline Corn residue & - & - & - & 20 & 6 & 3,648 \\
\hline Wheat residue & - & - & - & 15 & 91 & 31 \\
\hline Sorghum residue & - & - & - & - & 7 & 18 \\
\hline Rice residue & - & - & - & 6 & 1 & - \\
\hline \multicolumn{7}{|l|}{ Processing residues } \\
\hline Bagasse & 250 & 250 & 250 & 735 & 558 & 598 \\
\hline Sweet sorghum pulp & - & - & - & 106 & 106 & 106 \\
\hline \multicolumn{7}{|l|}{ Grain ethanol } \\
\hline Corn & 13,544 & 13,544 & 13,544 & 14,985 & 14,985 & 14,985 \\
\hline Barley & 23 & - & 1 & - & - & - \\
\hline Oats & - & 23 & 22 & - & - & - \\
\hline Sweet sorghum & - & - & - & 30 & 30 & 30 \\
\hline Total & 13,818 & 13,818 & 13,818 & 28,701 & 28,701 & 28,701 \\
\hline
\end{tabular}

(a lower cropland demand) shown in Figure 2. This climate change-induced decrease in cropland rental rate is even more pronounced under RFS2. The lower cropland rental rate also helps explain the increment in cropland conversion for pasture use shown in Figure 3, as the land opportunity cost decreases. Moreover, the RFS2 program raises cropland rental rate, as the demand for cropland increases.

5.3. Fuel Ethanol Production. Table 7 provides a comparison of feedstock-specific fuel ethanol production across the scenarios. It appears that in the absence of climate change, switchgrass-as a dedicated energy crop-provides the majority of cellulosic ethanol under RFS2. With climate change, however, a greater amount of crop residues and other kinds of dedicated energy crops are used for cellulosic ethanol production, partially replacing switchgrass-based ethanol. In particular, under the RFS2 Canadian scenario, corn residue delivers significantly more ethanol than under other scenarios. In brief, the presence of climate change reduces the biofuel delivery potential of switchgrass and diversifies the biofuel feedstock portfolio with a focus on conventional crop residues.

Table 8 provides a regional breakdown of cellulosic ethanol production derived from major feedstocks under RFS2 scenarios. As it shows, the "hotter and drier" Canadian climate significantly improves the corn residue-based ethanol production in the Lake States region, while reducing the switchgrass-based production in the Corn Belt region. Recall that in Table 2, the dryland corn yield (and, hence, the residues) is assumed to increase more in the Lake States region than in other regions under the Canadian climate, whereas the switchgrass yield in the Corn Belt is assumed
TABLE 8: Regional distribution of cellulosic ethanol production in million gallons per year by major feedstocks, 2030.

\begin{tabular}{lcccc}
\hline Feedstock & Region & RFS2 & RFS2HC & RFS2CC \\
\hline \multirow{4}{*}{ Switchgrass } & Corn belt & 6,209 & 6,119 & 4,865 \\
& Great plains & 1,414 & 2,582 & 1,748 \\
& Lake states & 1,044 & 866 & 560 \\
& Northeast & 289 & 280 & 224 \\
& South central & 2,161 & 1,861 & 805 \\
& Southeast & 2 & 132 & 0 \\
& Southwest & 1,625 & 963 & 809 \\
\hline Subtotal & & 12,744 & 12,804 & 9,011 \\
\hline \multirow{3}{*}{ Corn residue } & Corn belt & 0 & 0 & 437 \\
& Lake states & 0 & 0 & 3,203 \\
Subtotal & Northeast & 20 & 6 & 8 \\
\hline Total & & 20 & 6 & 3,648 \\
\hline
\end{tabular}

to have noteworthy reduction. For the relatively "milder" Hadley climate, more switchgrass-based production would occur in the Great Plains region, as the switchgrass yield is assumed to be increasing in the Great Plains region but decreasing in the South Central and the Southwest regions.

\section{Sensitivity Analysis on Energy Crop Mix}

A sensitivity analysis on energy crops mix is conducted to examine the potential changes in model outcomes, since the presence of an expanded set of energy crops may alter the RFS2 implications for US agriculture [33] and thus 
TABLE 9: RFS2 scenarios for sensitivity analysis on energy crops mix.

\begin{tabular}{lcccc}
\hline \multirow{2}{*}{ Scenario } & \multicolumn{2}{c}{ RFS2 mandate } & Climate change \\
& Switchgrass & Energy sorghum & None & Hadley \\
RFS2-ES & $\sqrt{ }$ & $\sqrt{ }$ & $\sqrt{ }$ \\
RFS2HC-ES & $\sqrt{ }$ & $\sqrt{ }$ & & \\
RFS2CC-ES & $\sqrt{ }$ & $\sqrt{ }$ & & $\sqrt{ }$ \\
\hline
\end{tabular}

TABLE 10: Proxy climate change effects on energy sorghum yields in percentage changes, 2030.

\begin{tabular}{|c|c|c|c|c|}
\hline & \multicolumn{2}{|c|}{ Hadley } & \multicolumn{2}{|c|}{ Canadian } \\
\hline & Dryland & Irrigated & Dryland & Irrigated \\
\hline Corn belt & 117.31 & & 87.84 & \\
\hline Great plains & 56.22 & 24.59 & 71.19 & 31.33 \\
\hline Northeast & 33.32 & & 27.54 & \\
\hline Pacific southwest & 107.46 & 39.03 & 52.88 & 45.06 \\
\hline Rocky mountains & 107.46 & 28.10 & 52.88 & 49.49 \\
\hline South central & 33.70 & 11.95 & 28.42 & 9.69 \\
\hline Southeast & 31.98 & & 25.34 & \\
\hline Southwest & 34.85 & 18.30 & 52.00 & 17.09 \\
\hline
\end{tabular}

Data source: U.S. National Assessment [10].

TABLE 11: U.S. agriculture welfare changes relative to base in \$2004 billion dollars under alternative RFS2 sensitivity scenarios, 2030.

\begin{tabular}{lccccccc}
\hline & & \multicolumn{3}{c}{ RFS2 energy sorghum } \\
& None & Change from RFS2 & Hadley & Change from RFS2HC & Canadian & Change from RFS2CC \\
\hline Consumer surplus & -1.27 & 1.86 & 12.68 & 0.32 & 9.36 & 1.12 \\
Producer surplus & 4.32 & -5.16 & 0.22 & -2.98 & 0.56 & -3.61 \\
\hline
\end{tabular}

the potential counteracting effects of RFS2 against adaptation-adjusted climate change on US agriculture.

To examine the implications of higher yielding energy crops, "energy sorghum" [34] is added into the energy crops mix for the analysis. The sensitivity scenarios employed are shown in Table 9. Each scenario includes both switchgrass and energy sorghum as dedicated energy crops and assumes the presence of RFS2 mandates with or without climate change. The reason that "energy sorghum" is particularly selected is because sorghum crop species fares better than most crops under climate change-as detailed in the data section next. This positive yield effect can imply that the RFS2 "burden" can get reduced more easily under climate change if the climate change-favored crop species are utilized to provide ethanol feedstocks.

6.1. Data for Sensitivity Analysis. The energy sorghum crop budgets were constructed based on Texas AgriLife Extension experimental data, and in general, the energy sorghum yields are more than twice the yields of switchgrass [34].

The estimates of adaptation-adjusted climate change effects on grain sorghum production are used as proxy for climate change effects on energy sorghum. Table 10 presents the estimated adaptation-adjusted climate change effects on energy sorghum yields, for both dryland and irrigated conditions if applicable, in different regions. The effects appear to be uniformly positive and fairly large under both the Hadley and Canadian climate change scenarios.

6.2. Sensitivity Analysis Results. Table 11 presents the estimated US agricultural welfare changes relative to the "no climate change, no RFS2" base scenario. Again, we find that without climate change, agricultural producer income increases whereas agricultural consumer surplus decreases.

With climate change, however, the increases in producer income get smaller, with the Hadley climate having greater negative effects. Consumer surplus, on the other hand, sees significant increases, with the Hadley climate having larger positive effects. In general, the changes in energy crops mix do not change the direction of welfare changes relative to the baseline. Nonetheless, the magnitudes of the changes associated with the energy sorghum mix are fairly smaller, compared to the counterpart switchgrass only scenarios (as in the main results). In other words, the introduction of high-yielding energy sorghum considerably dilutes the RFS2 impacts on US agricultural welfare-to the extent that the effects of adaptation-adjusted climate change dominate.

Table 12 presents the 2030 price and production indices for both crop and livestock under alternative sensitivity scenarios. As similar to the findings in Table 4, the inclusion of climate change expands crop production and in turn results in lower price indices. The climate change effects are less 
TABLE 12: Crop and livestock fisher indices relative to base (base $=100)$ under alternative RFS2 sensitivity scenarios, 2030.

\begin{tabular}{lcccccc}
\hline & & & RFS2 energy sorghum & & \\
& None & Change from RFS2 & Hadley & Change from RFS2HC & Canadian & Change from RFS2CC \\
\hline Crops & & & & & & \\
Price & 102.90 & -2.74 & 84.51 & -0.66 & 116.58 & -1.41 \\
$\quad$ Quantity & 100.47 & 1.83 & 120.41 & 0.83 & & 0.93 \\
Livestock & & & & & 97.64 & -0.32 \\
$\quad$ Price & 100.29 & -0.75 & 96.10 & -0.17 & 103.25 & 0.05 \\
Quantity & 99.95 & 1.30 & 104.04 & 0.12 & & \\
\hline
\end{tabular}

TABLE 13: Feedstock-specific ethanol production under alternative RFS2 sensitivity scenarios, 2030.

\begin{tabular}{|c|c|c|c|c|c|c|}
\hline & \multicolumn{6}{|c|}{ RFS2 energy sorghum } \\
\hline & None & Change from RFS2 & Hadley & Change from RFS2HC & Canadian & Change from RFS2CC \\
\hline \multicolumn{7}{|l|}{ Cellulosic ethanol } \\
\hline \multicolumn{7}{|l|}{ Dedicated energy crops } \\
\hline Switchgrass & - & $-12,744$ & - & $-12,804$ & - & $-9,011$ \\
\hline Hybrid poplar & - & 0 & - & -58 & - & -218 \\
\hline Willow & - & -61 & - & -55 & - & -57 \\
\hline Energy sorghum & 13,023 & 13,023 & 13,103 & 13,103 & 13,116 & 13,116 \\
\hline \multicolumn{7}{|l|}{ Crop residues } \\
\hline Corn residue & - & -20 & - & -6 & - & $-3,648$ \\
\hline Wheat residue & - & -15 & - & -91 & - & -31 \\
\hline Sorghum residue & - & 0 & - & -7 & - & -18 \\
\hline Rice residue & - & -6 & - & -1 & - & 0 \\
\hline \multicolumn{7}{|l|}{ Processing residues } \\
\hline Bagasse & 663 & -72 & 583 & 26 & 570 & -28 \\
\hline Sweet sorghum pulp & - & -106 & - & -106 & - & -106 \\
\hline \multicolumn{7}{|l|}{ Grain ethanol } \\
\hline Corn & 14,985 & 0 & 14,985 & 0 & 14,985 & 0 \\
\hline Barley & 30 & 30 & - & 0 & 28 & 28 \\
\hline Oats & - & 0 & 30 & 30 & 2 & 2 \\
\hline Sweet sorghum & - & -30 & - & -30 & - & -30 \\
\hline Total & 28,701 & 0 & 28,701 & 0 & 28,701 & 0 \\
\hline
\end{tabular}

significant on livestock indices. The energy sorghum mix does not bring about significant changes (albeit noticeable) in the indices compared to the counterpart switchgrass only scenarios.

Table 13 summarizes the fuel ethanol production under alternative sensitivity scenarios by feedstock. As the table shows, the introduction of climate change enlarges the role of energy sorghum in providing cellulosic ethanol, eliminating switchgrass-based and many other kinds of cellulose-based ethanol. This result suggests that under climate change, heattolerant (as indicated by the assumed positive climate change effects shown in Table 10) and high-yielding dedicated energy crop such as energy sorghum could gain an extra advantage in providing RFS2 biofuel feedstocks.

Table 14 further presents a regional breakdown of energy sorghum-based ethanol production by 2030 . Under both climate change scenarios, there is a projected regional shift of energy sorghum-based production from the Southern regions to the Corn Belt and the Great Plains regions. Recall that the energy sorghum yields are assumed to increase in these regions as shown in Table 10 and these regions are among the major sorghum production regions.

\section{Conclusions and Discussion}

The "synergy," or perhaps the opposite, between mitigation and climate change effects on agriculture is explored. The research presented in this paper focuses on the US agricultural sector under projected climate change, incorporating both RFS2-a large-scale agriculture-based activity with some GHG mitigation characteristics-and climate change effects (with autonomous adaptation) on agriculture, into FASOMGHG to investigate the aggregate effects of the two on US agriculture. Meanwhile, the analysis compares the climate change scenarios with and without RFS2, to gain an insight whether RFS2 adds to or counteracts the effects of climate change, as well as how climate change affects RFS2. 
TABLE 14: Regional distribution of energy sorghum-based ethanol production in million gallons per year under alternative scenarios, 2030.

\begin{tabular}{lccc}
\hline Region & RFS2-ES & RFS2HC-ES & RFS2CC-ES \\
\hline Corn belt & 3,725 & 4,018 & 5,206 \\
Great plains & 5,068 & 5,631 & 5,631 \\
Northeast & 21 & 23 & 14 \\
Rocky mountains & 261 & 57 & 0 \\
Pacific southwest & 0 & 24 & 0 \\
South central & 1,250 & 2,835 & 1,661 \\
Southeast & 107 & 103 & 98 \\
Southwest & 2,592 & 413 & 507 \\
\hline Total & 13,023 & 13,103 & 13,116 \\
\hline
\end{tabular}

In terms of climate change incorporation, this study largely follows the methods used in Reilly et al. (2001) [26] and McCarl (2006) [27]. For biofuels it follows the work of Beach and McCarl (2010) [28] to include biofuels production and processing and RFS2 scenarios.

The aggregate effects of RFS2 and climate change are projected to be positive for both agricultural consumer welfare and agricultural producer income. While offsetting each other, the beneficial impacts of climate change dominate the negative effects of RFS2 on consumer welfare, and the supporting effects of RFS2 outweigh the decreasing effects of climate change on producer income-a "synergy" in terms of welfare effects between mitigation and climate change is thus suggested.

A closer examination of agricultural price and production indices further shows that climate change, with adaptation considered, can induce increases in crop and livestock production, suppressing price levels to the extent that agricultural producer income decreases. RFS2, on the other hand, raises prices and diminishes conventional agricultural production, resulting in greater producer surplus and noticeable losses in agricultural consumer welfare.

Regarding cropland usage, under climate change, markedly less cropland is estimated to be devoted to crop production. RFS2, in contrast, induces greater use of cropland for crop production, counteracting the climate change effects on cropland usage. Moreover, a comparison of land use change between the scenarios suggests that under climate change, with adaptation included, the US agricultural sector can accommodate both conventional crops production and the farming of RFS2 energy crops without disrupting the general land use allocation. Thereby the controversy over indirect land use change caused by RFS2 may be alleviated.

In brief, the RFS2 impact and the climate change impact on US agriculture act in opposite directions, as demonstrated in the aspects of agricultural welfare, agricultural commodity price and production, and land use. Nonetheless, a "synergy" measured by agricultural welfare changes is indicated.

As for RFS2 biofuels production, the model results suggest that climate change alters the feedstock mix by inducing greater use of crop residues and non-switchgrass energy crops for cellulosic ethanol production. A sensitivity analysis on including high-yielding energy sorghum under climate change further suggests that climate change would enlarge the role of heat-tolerant energy crops such as energy sorghum in fulfilling RFS2 mandates. In addition, with high-yielding energy sorghum, the RFS2 effects on US agricultural welfare would become much less pronounced, to the extent that the climate change effects dominate.

The research presented in this paper is subject to several limitations, however. First, the data on climate change effects on crop production performance are obtained from crop simulation models mentioned in the literature review section, and thus this research is subject to the limitations of those crop models.

Second, the No RFS2 and RFS2 biofuel volumes exogenous to the FASOMGHG model were introduced based on EPA-compiled AEO 2007 and 2009 projections [22], and therefore the assumed competitiveness of biofuels against conventional liquid fuels in this study is subject to the limitations of AEO studies. Should the biofuels turn out to be less economically competitive than the conventional liquid fuels or not well received by market due to constraints like "blend wall" [35] in the future, the obligated parties under RFS2 then may have to pay more for the renewable identification numbers (RIN) to comply with the RFS2 mandates $[35,36]$, and consequently consumers may incur some losses as well. Moreover, the potential impacts of climate change on the relative competitiveness of sugar- and corn-biofuels produced in the US and Brazil were not explicitly considered (although that underlain the AEO analysis where 31.7 of the 36 BGY were produced domestically), which can have implications for the No RFS2 and RFS2 volume assumptions $[37,38]$. Hence, the No RFS2 and RFS2 volumes used for climate change scenarios may need to be revised to reflect those potential changes.

Third, the rest of the world (ROW) grain supply is assumed to respond to climate change only following Reilly et al. (2001) [26] and McCarl (2006) [27]. The RFS2 shocks on ROW's grain supply were not considered.

Fourth, the Hadley and the Canadian climate projections employed in this study were derived based on the IPCC's IS92A emissions scenario [10]. According to IPCC (2000) [39], this IS92A GHG emissions scenario is often referred to as the "business-as-usual" scenario, and thereupon climate change mitigation efforts such as RFS2 are not well reflected in this scenario. This may imply that the estimates of climate change effects employed by this study are overestimated ones-against the backdrop of RFS2 among many other GHG mitigation activities.

Given earlier, future research may have to utilize moredeveloped estimates of climate change effects and/or policy shocks on agriculture and consider the climate feedbacks of mitigation activities. Further, an examination of regional effects would be desirable, given that the distributional effects of climate change, in conjunction with RFS2, on agriculture may be more relevant to agricultural producers. 


\section{References}

[1] J. M. Antle, Agriculture and the Food System: Adaptation to Climate Change, Resources for the Future, Washington, DC, USA, 2009.

[2] IPCC WGI, Climate Change 2007: The Physical Science Basis. Contribution of Working Group I To the Fourth Assessment Report of the Intergovernmental Panel on Climate Changeeds, Cambridge University Press, New York, NY, USA, 2007.

[3] P. Smith and J. E. Olesen, "Synergies between the mitigation of, and adaptation to, climate change in agriculture," Journal of Agricultural Science, vol. 148, no. 5, pp. 543-552, 2010.

[4] IPCC WGI, Climate Change 2007: Impacts, Adaptation and Vulnerability. Contribution of Working Group II to the Fourth Assessment Report of the Intergovernmental Panel on Climate Changeeds, Cambridge University Press, New York, NY, USA, 2007.

[5] R. J. T. Klein, E. L. F. Schipper, and S. Dessai, "Integrating mitigation and adaptation into climate and development policy: three research questions," Environmental Science and Policy, vol. 8, no. 6, pp. 579-588, 2005.

[6] C. Rosenzweig and F. N. Tubiello, "Adaptation and mitigation strategies in agriculture: an analysis of potential synergies," Mitigation and Adaptation Strategies for Global Change, vol. 12, no. 5, pp. 855-873, 2007.

[7] D. Schimmelpfennig, J. Lewandrowski, J. Reilly, M. Tsigas, and I. Parry, Agricultural Adaptation to Climate Change: Issues of Longrun Sustainability, U.S. Department of Agriculture, Washington, DC, USA, 1996.

[8] R. C. Izaurralde, R. A. Brown, and N. J. Rosenberg, U.S. Regional Agricultural Production in 2030 and 2095, Response To $\mathrm{CO}_{2}$ Fertilization and Climate Model (HADCM2) Projections of Greenhouse Gas-Forced Climate Change, Pacific Northwest National Laboratories, Washington, DC, USA, 1999.

[9] R. C. Izaurralde, N. J. Rosenberg, R. A. Brown, and A. M. Thomson, "Integrated assessment of Hadley Center (HadCM2) climate-change impacts on agricultural productivity and irrigation water supply in the conterminous United States. Part II. Regional agricultural production in 2030 and 2095," Agricultural and Forest Meteorology, vol. 117, no. 1-2, pp. 97-122, 2003.

[10] J. Reilly, F. Tubiello, B. McCarl et al., "U.S. Agriculture and climate change: new results," Climatic Change, vol. 57, no. 1-2, pp. 43-69, 2003.

[11] F. N. Tubiello, C. Rosenzweig, R. A. Goldberg, S. Jagtap, and J. W. Jones, "Effects of climate change on US crop production: simulation results using two different GCM scenarios. Part I: wheat, potato, maize, and citrus," Climate Research, vol. 20, no. 3, pp. 259-270, 2002.

[12] W. Schlenker and M. Roberts, "Estimating the impact of climate change on crop yields: the importance of nonlinear temperature effects," NBER Working Paper 13799, 2008.

[13] R. M. Adams, C. Rosenzweig, R. M. Peart et al., "Global climate change and US agriculture," Nature, vol. 345, no. 6272, pp. 219224,1990

[14] R. M. Adams, R. A. Fleming, C.-C. Chang, B. A. McCarl, and C. Rosenzweig, "A reassessment of the economic effects of global climate change on U.S. agriculture," Climatic Change, vol. 30, no. 2, pp. 147-167, 1995.

[15] S. K. Rose and B. A. McCarl, "Greenhouse gas emissions, stabilization and the inevitability of adaptation: challenges for U.S. agriculture," Choices, pp. 15-18, 2008.
[16] B. A. McCarl and U. A. Schneider, "Greenhouse gas mitigation in U.S. agriculture and forestry," Science, vol. 294, no. 5551, pp. 2481-2482, 2001.

[17] U. A. Schneider and B. A. McCarl, "Economic potential of biomass based fuels for greenhouse gas emission mitigation," Environmental and Resource Economics, vol. 24, no. 4, pp. 291312, 2003.

[18] J. M. Reilly, "Climate change and agriculture: the state of the scientific knowledge," Climatic Change, vol. 43, no. 4, pp. 645650, 1999.

[19] D. Adams, R. Alig, B. A. McCarl et al., "FASOMGHG conceptual structure, and specification: documentation," 2005, http:// agecon2.tamu.edu/people/faculty/mccarl-bruce/papers/1212FASOMGHG_doc.pdf.

[20] R. Mendelsohn and A. Dinar, "Land use and climate change interactions," Annual Review of Resource Economics, vol. 1, no. 1, pp. 309-332, 2009.

[21] EIA, Annual Energy Outlook 2007: With Projections To 2030. Energy Information Administration, U.S. Department of Energy, Washington, DC, USA, 2007.

[22] EPA, Renewable Fuel Standard Program (RFS2) Regulatory Impact Analysis, U.S. Environmental Protection Agency, Washington, DC, USA, 2010.

[23] R. M. Adams, B. A. McCarl, K. Segerson et al., "Economic effects of climate change on US agriculture," in The Impact of Climate Change on the United States Economy, R. Mendelsohn and J. E. Neumann, Eds., pp. 18-54, Cambridge University Press, Cambridge, UK, 1999.

[24] C.-C. Chen and B. A. McCarl, "An investigation of the relationship between pesticide usage and climate change," Climatic Change, vol. 50, no. 4, pp. 475-487, 2001.

[25] P. Gleick and B. D. Adams, Water: The Potential Consequences of Climate Variability and Change for Water Resources of the United States, Pacific Institute, Oakland, Calif, USA, 2000.

[26] J. M. Reilly, J. Hrubovcak, J. Graham et al., Agriculture: The Potential Consequences of Climate Variability and Change For the United States, Cambridge University Press, New York, NY, USA, 2001, US National Assessment of the Potential Consequences of Climate Variability and Change, US Global Change Research Programeds.

[27] B. A. McCarl, "US agriculture in the climate change squeeze: part 1: sectoral sensitivity and vulnerability," 2006, National Environmental Trust, http://agecon2.tamu.edu/people/faculty/ mccarl-bruce/689cc/topic5b_Agriculture\%20in\%20the\%20climate $\% 20$ change $\% 20$ squeezl.pdf.

[28] R. Beach and B. A. McCarl, U.S. Agricultural and Forestry Impacts of the Energy Independence and Security Act: FASOM Results and Model Description, Prepared For U.S. Environmental Protection Agency Office of Transportation and Air Quality, RTI International, Research Triangle Park, NC, USA, 2010.

[29] EIA, Annual Energy Outlook 2009: With Projections To 2030. Energy Information Administration, U.S. Department of Energy, Washington, DC, USA, 2009.

[30] R. Schnepf and B. D. Yacobucci, Renewable Fuel Standard (RFS): Overview and Issues, Congressional Research Service, 2013.

[31] L. Tao and A. Aden, Techno-Economic Modeling to Support the EPA Notice of Proposed Rulemaking (NOPR), National Renewable Energy Laboratory (NREL), 2008.

[32] A. Aden, Biochemical Production of Ethanol from Corn Stover: 2007 State of Technology Model, National Renewable Energy Laboratory (NREL), 2008. 
[33] B. A. McCarl and Y. W. Zhang, "Use of advanced energy crops: an economic analysis of food, greenhouse gas and energy implications," in Advances in Energy Research, M. J. Acosta, Ed., vol. 6, Nova Science Publishers, Hauppauge, NY, USA, 2011.

[34] B. F. McCutchen, R. V. Avant Jr., and D. Baltensperger, "Hightonnage dedicated energy crops: the potential of sorghum and energy cane," in Reshaping American Agriculture to Meet its Biofuel and Biopolymer Roles, Proceedings of the Twentieth Annual Conference of the National Agricultural Biotechnology Council, hosted by the Ohio State University, Columbus, OH, June 3-5, 2008, A. Eaglesham, S. A. Slack, and R. W. F. Hardy, Eds., pp. 119-122, National Agricultural Biotechnology Council, Ithaca, NY, USA, 2008.

[35] FAPRI, "A question worth billions: why isn't the conventional RIN price higher?” FAPRI-MU Report 12-12, 2012.

[36] L. McPhail, P. Westcott, and H. Lutman, The Renewable Identification Number System and U.S. Biofuel Mandates, Economic Research Service, U.S. Department of Agriculture, 2011.

[37] S. Meyer, J. Schmidhuber, and J. Barreiro-Hurle, "Intra-industry trade in biofuels: how environmental legislation fuels resource use and GHG emissions," ESA Working Paper 12-08, Agricultural Development Economics Division, Food and Agriculture Organization of the United Nations, 2012.

[38] FAPRI, "US biofuel baseline and impact of E-15 expansion on biofuel markets," FAPRI-MU Report 02-12, 2012.

[39] N. Nakicenovic and R. Swart, Eds., Emissions Scenarios, IPCC, Cambridge University Press, Cambridge, UK, 2000. 

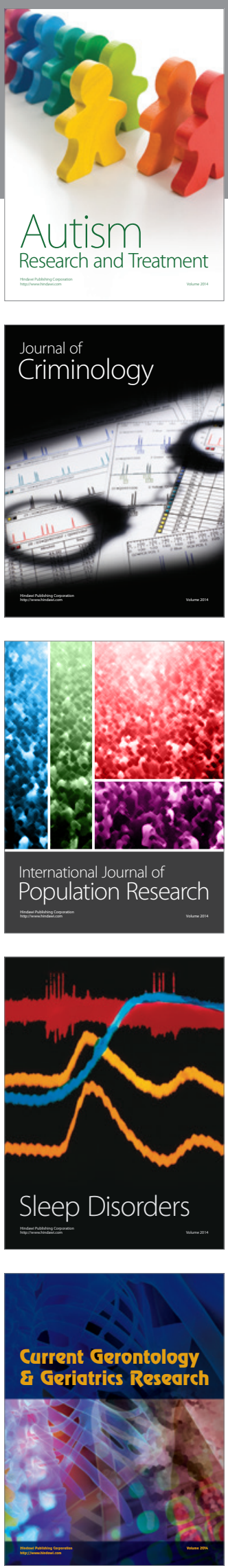
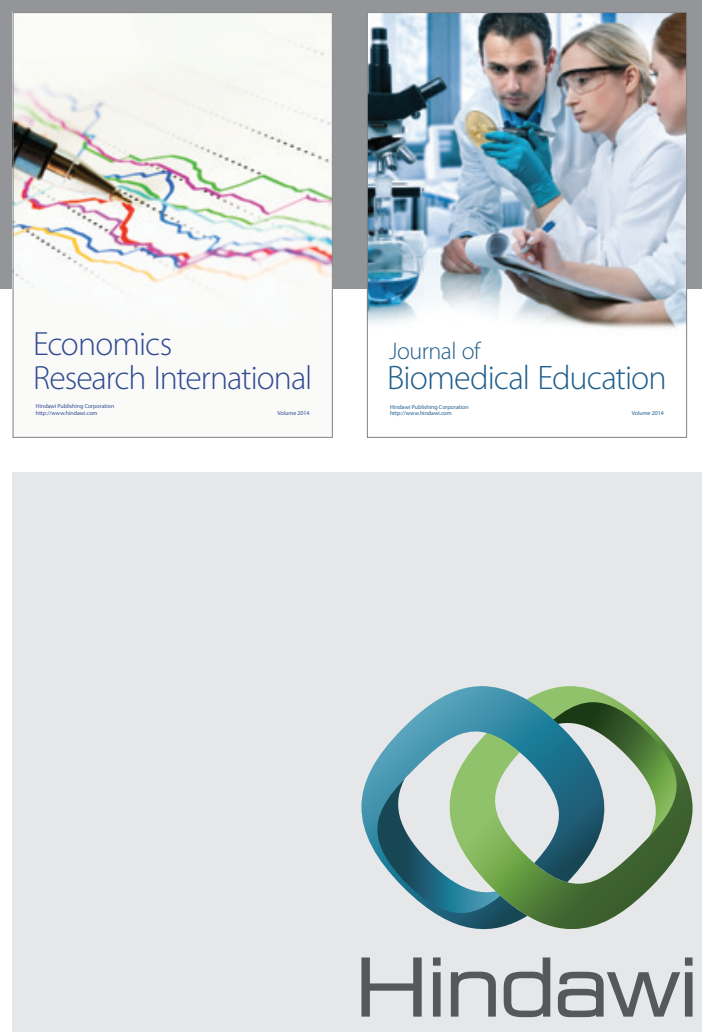

Submit your manuscripts at

http://www.hindawi.com
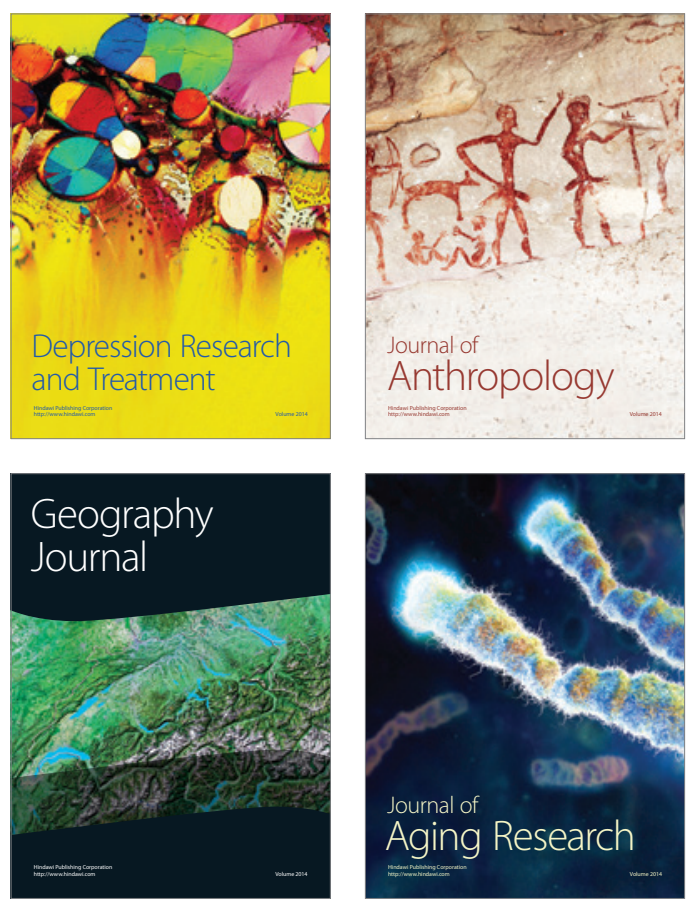
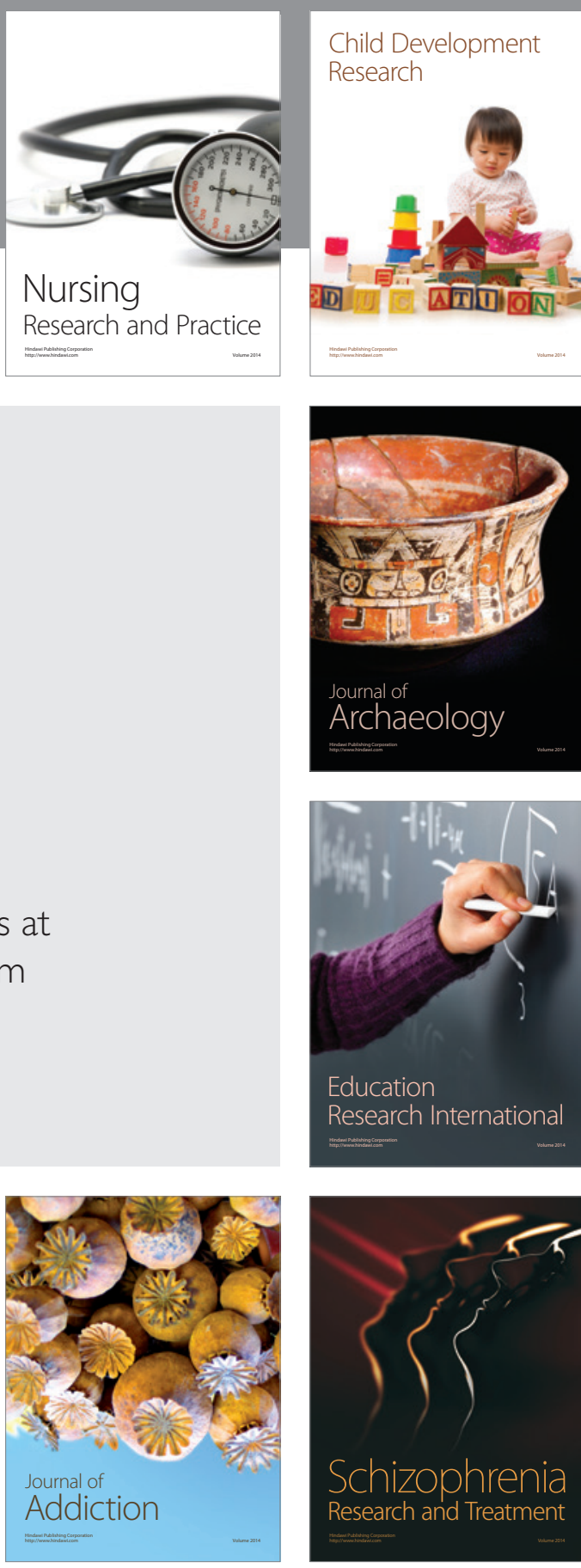

(D)
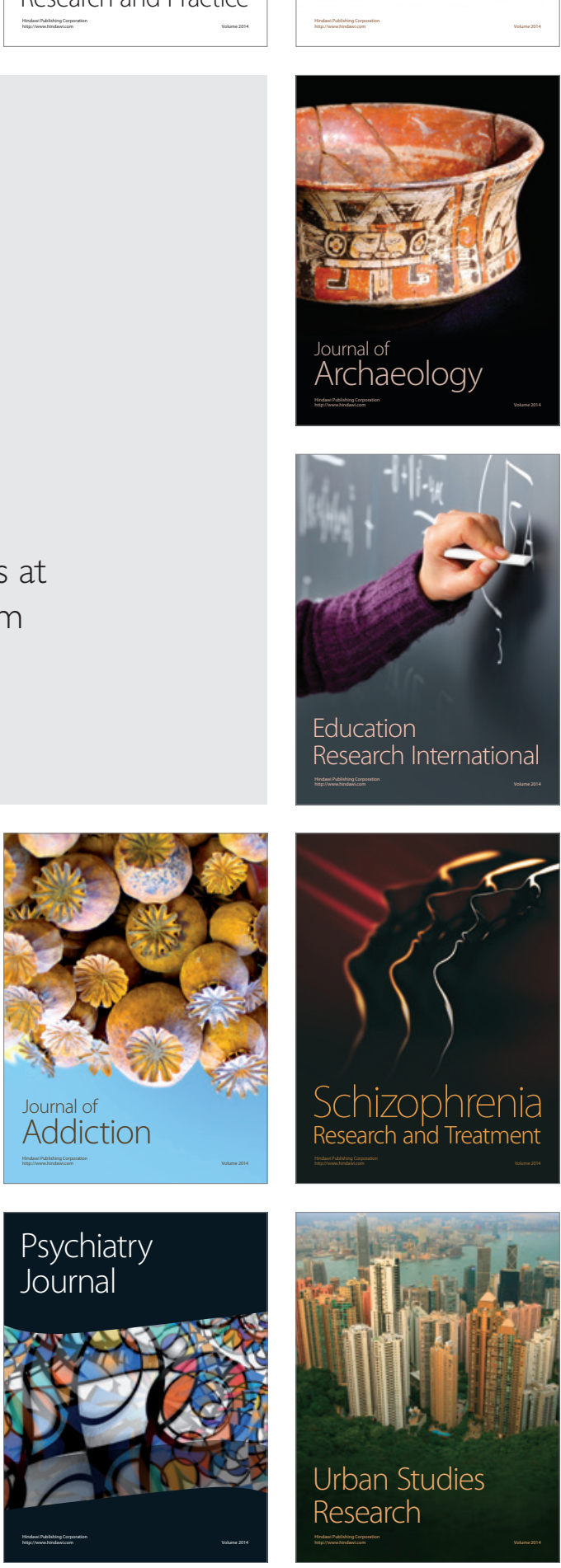